\title{
Restricciones en la gestión de recursos humanos en las organizaciones públicas
}

Restrictions in the management of human resources in public organizations

\section{Hugo Cormick}

Magister en Administración Pública, FCE-UBA. Profesor Titular Ordinario Gestión de Recursos Humanos en el Sector Público, Universidad Nacional de Moreno.

hcormick@unm.edu.ar htcormick@gmail.com
Fecha de recepción 29.4 .13

Fecha de aceptación 25.7.13

\section{Resumen}

La gestión de los recursos humanos en las administraciones públicas está atravesada por el debate respecto de la "interferencia" de la política en las diversas etapas de su despliegue, considerada como un obstáculo para un racional desempeño organizacional. Ante esta interferencia se propicia la aplicación de criterios técnicos para el logro de los objetivos de las organizaciones públicas. Sin embargo, la crítica suele ignorar la presencia de la dimensión presupuestaria en la toma de decisiones sobre esta gestión. Estas tres dimensiones: técnica, política y presupuestaria operan como restricciones que configuran la real gestión de recursos humanos en el ámbito público, por lo que se propone una mirada que dé cuenta de este entrecruzamiento sin caer en un discurso unilateralmente prescriptivo.

Palabras clave: Administración pública - Recursos Humanos - Presupuesto Público -

Técnica vs. Política

\section{Abstract}

The human resources management in public administrations is crossed by the debate about the "interference" of politics in different stages of its development, which is considered as an obstacle for a rational organizational performance. Given this interference, the application of technical criteria for achieving the objectives of public organizations is usually proposed. However, this proposal 
tends to ignores the presence of the budgetary dimension in making decisions on this management. These three dimensions: technical, political and budgetary, operate as restrictions for human resources management in the public sphere; accordingly, proposes an approach to this question in order to account that interaction, thus avoiding an unilaterally prescriptive discourse.

Key words: Public administration - Human Resources - Technique vs Politics - Public Budget

\section{Introducción}

La gestión de los recursos humanos en las administraciones públicas está permanentemente atravesada por el debate respecto de la "interferencia" de la política en las diversas etapas de su desarrollo, entendiendo como tal los procesos de planificación, organización del trabajo, gestión del empleo, del rendimiento, de las compensaciones, del desarrollo y de las relaciones sociales y humanas (Longo 2004). Esta interferencia es considerada como un obstáculo para un racional desempeño organizacional, ante la que se propicia la aplicación de criterios eminentemente técnicos como requisito indispensable para que las organizaciones públicas puedan alcanzar sus objetivos.

Cuestiones como el histórico spoil system ${ }^{1}$ en la tradición del empleo público en Estados Unidos o las significativas referencias al clientelismo en el sistema de reclutamiento de recursos humanos en las administraciones públicas de América Latina, ${ }^{2}$ deberían llevar a pensar en que la presencia de lo político en la gestión de los recursos humanos no ha sido un tema de sencilla resolución.

Por ejemplo, en un reciente trabajo coordinado por Francisco Longo y Carles Ramió (2008:10-11) se afirma categóricamente que

A pesar de las enormes diferencias existentes [entre los sistemas de servicio civil en los países de América Latina], se pueden establecer algunos puntos de contacto entre los mismos. En términos generales los sistemas responden más a impulsos clientelares y políticos que a impulsos profesionales, en un contexto donde los incentivos económicos y de estatus de los servidores públicos son muy bajos. Estos dos elementos implican una gran inestabilidad de los recursos humanos de las administraciones públicas de la región. 
Una mirada similar propone Guillermo Schweinheim (2011:18-19) al señalar que

En América Latina ha habido escasos avances en materia de institucionalización del servicio civil. En general, el personal público ha sido seleccionado o ha avanzado en la carrera administrativa por criterios de adscripción partidaria, clientelismo político y social, o por redes sociales y familiares de acceso al empleo público. ... Por otra parte, el empleo público de muchos países de mayor desarrollo relativo se vio sometido a relaciones contractuales precarizadas en los años 90 y hasta bien entrada la década siguiente.

Si se analiza con más detenimiento qué significa hablar de lo político o de lo técnico, podría entenderse que este debate requiere de un estudio más riguroso, tratando de indagar el papel de cada uno de estos factores en los procesos de gestión de recursos humanos. Lo anterior es particularmente relevante en el caso de los estados latinoamericanos en los que es posible identificar una dificil configuración de la relación entre Estado y sociedad, que da cuenta de la baja autonomía de aquél respecto del poder económico concentrado y una relativa desestructuración de los sectores sociales subordinados. A esto se le agregan condiciones sociocontextuales de mayores carencias que en los países desarrollados, así como relativa informalidad en las relaciones laborales. En lo que hace a la gestión de recursos humanos se produce la coexistencia entre definiciones formalistas y prácticas patrimonialistas, y un escenario de reformas tensionado entre la racionalidad técnica y las condiciones culturales y políticas del medio en que pretenden ser implantadas.

Ahora bien, la gestión de los recursos humanos en las administraciones públicas ha sufrido cambios significativos, particularmente en Argentina y de modo especial durante la década de 1990 que se inscriben en decisiones de carácter más amplio, relacionadas con requerimientos fiscales, dirigidas a la reducción del déficit estatal, y no necesariamente en principios técnicos relacionados con la óptima gestión de estos recursos ni en una estrategia que pueda identificarse como de carácter político. Pese a la referencia anterior, el aspecto presupuestario no suele ser considerado como dimensión relevante en la definición de las políticas de recursos humanos, más allá de la presencia de ejemplos muy concretos, tales como la sistemática reducción del empleo público, a través de retiros voluntarios, jubilaciones anticipadas, proliferación de plantas de contratados o personal no permanente, pase de agentes a situación de disponibilidad, despidos por superposición de estructuras, despidos directos con o sin indemnización o congelamientos de vacantes, que fueron ampliamente aplicados durante la década de 1990 y que tuvo su máxima expresión en la reducción salarial aplicada al sector público nacional a comienzos de 
la década siguiente, en un esfuerzo (vano) para atenuar una brutal crisis económica en Argentina. Todos estos ejemplos manifiestan la significativa presencia de los factores presupuestarios en las decisiones sobre la política de recursos humanos.

En virtud de lo anterior, el presente trabajo propone la existencia de un continuo entrelazamiento de las dimensiones técnica, presupuestaria y política sobre las decisiones relacionadas con la gestión de recursos humanos, y busca mostrar algunos efectos de la presencia coexistente de estas dimensiones. Estas variables actuarían como restricciones en la medida en que su intervención tiene efectos directos sobre el ingreso de personal, de manera indirecta, sobre la calidad de su gestión y, finalmente, sobre los productos generados por las organizaciones. Cabe señalar que estas restricciones no son abstractas, sino que se hacen presentes en la historia concreta de cada organización, dando lugar a formas específicas de articulación de recursos, de manera que, organizaciones "similares" pueden llegar a una conformación de sus recursos humanos relativamente diferente, aunque igualmente atravesada por estas mismas variables. Asimismo, se tratará de mostrar cuáles son los instrumentos específicos que permiten identificar la intervención concreta de estas restricciones, a fin de diferenciar las modalidades específicas que puede adquirir su presencia en distintas organizaciones públicas. En un trabajo previo, se aplicó este análisis al caso de una organización en particular (Cormick 2009).

Si bien la dimensión normativa suele entenderse como determinante en la gestión de recursos humanos de las organizaciones públicas, su intervención será incorporada como un aspecto instrumental de las dimensiones mencionadas, ya que, si bien las normas facilitan o restringen las orientaciones en el reclutamiento de recursos humanos en las organizaciones públicas, éstas cuentan con capacidad para adaptar la normativa a sus necesidades específicas. A este respecto, Longo (2004) señala cómo ciertas perspectivas tienden a sobrevalorar la relevancia de la dimensión jurídica, omitiendo su subordinación a otros aspectos de la gestión estatal. En lo que hace a la dimensión cultural, como valioso entramado no formal de las organizaciones, sus impactos podrían considerarse como subsumidos en lo que, en este trabajo, se identificará como propio del ámbito de la política.

Con esta identificación se propone un análisis de la gestión de recursos humanos en las organizaciones públicas que, a partir de la comprensión de las variables que intervienen en su definición, facilite la identificación de las estrategias orientadas a su mayor fortalecimiento y profesionalización, propiciando que se evite una perspectiva exclusivamente prescriptiva en la enunciación de la política de recursos humanos y que permita la comprensión de los intereses y necesidades de los diversos actores en juego: autoridades, ciudadanos, trabajadores, organizaciones políticas y de la sociedad civil. 
Por otra parte, y siguiendo los planteos antes mencionados, se tratará de mostrar que tales restricciones son resultado de necesidades contradictorias. Si bien, las argumentaciones desde el sentido común suponen la necesidad de dar prioridad a la dimensión técnica, no cabe duda de que la presencia frecuente de los aspectos presupuestarios y políticos en la definición de las políticas de recursos humanos, obliga a explicar a qué causas, no necesariamente lineales, obedecen estas presencias y qué efectos generan sobre la gestión de las organizaciones.

A su vez, al actuar correctivamente sobre alguna de ellas, sin identificar adecuadamente el conjunto de causalidades que dio lugar a su presencia, se corre el riesgo de producir resultados conflictivos en el desempeño organizacional. Por ejemplo, si la aplicación de criterios políticos para la incorporación de recursos humanos facilita cierta legitimación y estabilidad del ápice de una organización, el reemplazo de este criterio por otros de carácter más técnico, si bien, en un sentido abstracto resultaría beneficioso para la profesionalización de la organización, en el corto plazo puede generar conflictos con actores afectados, ante los cuales no se cuente con recursos suficientes para sostener la decisión asumida. Cabe señalar, a su vez, que la aplicación de estos criterios contradictorios puede influir tanto sobre el ápice de la organización, sus niveles directivos o gerenciales o sobre los niveles más estrictamente técnicos (supuestamente no influenciados por aspectos políticos) e incluso, con otras características, respecto de los niveles organizacionales relacionados con la prestación de servicios administrativos y de mantenimiento. Lo anterior supone que, reconociendo la necesidad de modificar ciertas modalidades de gestión de los recursos humanos de las organizaciones públicas, en busca de su mayor profesionalización y jerarquización técnica, su estrategia de fortalecimiento será más eficaz en la medida en que identifique la complejidad de causas que dan lugar a determinadas modalidades de gestión, los actores que intervienen en ellas y las ventajas y perjuicios que se generan a consecuencia de estas decisiones.

Por último, la necesidad de responder a requerimientos técnicos en la gestión de recursos humanos se transforma en un aliciente para el fortalecimiento de las organizaciones públicas en una perspectiva de largo plazo, más allá de las ventajas inmediatas que pueden brindar otras formas de administración de estos recursos. El Cuadro 1 (vid.Apéndice) ofrece, tanto una definición sucinta de cada restricción, como su relevancia para las organizaciones, las posibles formas de medición de su presencia y algunas características destacadas de cada una.

Estas reflexiones se dan en un contexto en el que el estado nacional ha ampliado su intervención en diversos campos de la sociedad que anteriormente habían sido remitidos al mercado o simplemente omitidos de la agenda pública. Esta nueva forma de presencia estatal llevaría a suponer la necesidad de contar con agentes que respondan técnicamente a estos requerimientos y que cuenten con una adecuada comprensión de 
los objetivos que persigue la gestión gubernamental. A este respecto, es útil señalar que la perspectiva propiciada durante la década del noventa ponía el acento en la necesidad de reducir las intervenciones estatales, por lo que, más allá del acuerdo o disenso con estas políticas, era entendible la estrategia de restricción del empleo público. La situación actual no se corresponde con aquellos principios, aunque debería analizarse si las estrategias de gestión de recursos humanos son significativamente diferentes a las de los periodos anteriores.

\section{Acerca de las restricciones en juego}

\section{Restricción técnica}

Se entiende por restricción técnica aquella que, por efectos de las responsabilidades que enfrenta una organización, obliga a organizar sus recursos humanos dentro de los perfiles específicos que faciliten el cumplimiento de los objetivos propuestos. Podrá observarse que, en ocasiones (más o menos frecuentes) el cumplimiento de esta restricción no es el esperado y, seguramente, la capacidad de la organización para alcanzar sus objetivos quedará menguada. Sin embargo, un alejamiento extremo de los requerimientos técnicos de una organización enfrenta límites que ponen en riesgo su legitimidad y su capacidad de intervención en el ámbito de sus competencias.

Aquí cabe señalar que aquellas organizaciones más relacionadas con tecnologías legitimadas tienden a privilegiar más claramente la intervención de la restricción técnica, mientras que esta presencia se diluye en aquellas otras que no desarrollan tecnologías socialmente consolidadas o reconocidas por actores externos a la organización. El primer tipo corresponde a organizaciones educativas, de salud, de recaudación tributaria, de administración financiera, de control público, etc., mientras que el segundo grupo se acerca más típicamente a los ámbitos clásicos de la administración pública, manifestándose más precisamente en áreas como mantenimiento, despacho o mesa de entradas y también en los espacios identificados como de "gabinete" o aquellas organizaciones públicas cuyas clientelas organizacionales no cuentan con un complejo desarrollo técnico o con recursos de poder significativos. ${ }^{3}$

La restricción técnica puede ser medida por la proporción de recursos humanos que responden a perfiles específicamente técnico profesionales. La Tabla 1, en el Apéndice, muestra de una manera muy general esta presencia en el ámbito del escalafón correspondiente al Sistema Nacional de la Profesión Administrativa (SINAPA, hoy Sistema Nacional del Empleo Público, SINEP), el más numeroso de los colectivos laborales de la Administración Pública Nacional (APN). Aquí se observa el peso relativamente bajo del personal con formación universitaria en ese ámbito. Sin embargo, como puede observarse, el personal contratado presenta niveles de estudio superiores al personal permanente, lo que se manifiesta principalmente en la escasa presencia de agentes con- 
tratados que cuentan sólo con estudios primarios y una mayor proporción con estudios secundarios y de profesionales universitarios.

Si bien esta tabla no informa de manera directa sobre el peso de la restricción técnica, parece razonable aceptar que el requisito de profesionalidad para el ejercicio de funciones en la APN no tiene una presencia determinante en la selección y reclutamiento de sus recursos humanos. Lo anterior no debe omitir la necesidad de contar con agentes que realicen tareas no profesionales, aunque cabe explicitar que el aspecto más crítico de las organizaciones públicas se relaciona con la capacidad de planificación, formulación y evaluación de las políticas públicas, lo que requeriría niveles de formación técnico profesional. Sin duda, el mecanismo de selección más consistente con el respeto de esta restricción es la aplicación de concursos que permitan seleccionar candidatos que cuenten con competencias técnico profesionales acordes con los requerimientos de las organizaciones estatales. Esto no significa que haya una completa correlación entre este sistema de reclutamiento y la presencia de personal técnico para cumplir las tareas de la organización. En consonancia con la aplicación de principios técnicos, el estado nacional ha instaurado de manera taxativa el requisito de la selección de personal a través de concursos. Si bien su práctica ha sido errática desde la instauración de este principio, en estos últimos años se ha incrementado la convocatoria a concursos en diversas jurisdicciones. ${ }^{4}$

Este mismo análisis, aplicado a organizaciones específicas, permite ver una presencia relevante de la dimensión técnica. ${ }^{5}$ Lo que surge de esta observación es que la presencia técnica está fuertemente relacionada con exigencias externas de la organización, con las tecnologías de gestión que las gobiernan y con el "control" social sobre el desempeño organizacional. Este control social puede partir de organismos internacionales que establecen pautas de gestión organizacional, o de interlocuciones con instituciones académicas o con requerimientos establecidos normativamente que obligan a la presencia profesional para el ejercicio de la función de que se trata. En este sentido, ciertas tecnologías son apropiadas exclusivamente por determinadas corporaciones profesionales (abogados, función jurídica, contadores, función contable, etc.) mientras que otras son menos "apropiables" (planificación, formulación y evaluación de políticas) por lo que pueden ser disputadas por distintos perfiles profesionales y son permeables a presencias no profesionales.

\section{Restricción presupuestaria}

El concepto de restricción presupuestaria corresponde al rol de la dimensión presupuestaria en la capacidad de la organización para asignar adecuadamente los recursos (en este caso humanos). Puede considerarse como una restricción dominantemente externa en la medida en que las organizaciones tienen baja capacidad de intervención en las decisiones presupuestarias estructurales. 
La propia formulación presupuestaria, si bien inicia en cada organización, es consolidada por la Subsecretaría de Presupuesto del Ministerio de Economía y por la Secretaría de Evaluación Presupuestaria de la Jefatura de Gabinete de Ministros, que aplican los criterios que surgen de la perspectiva global con que cuenta el Poder Ejecutivo. El Congreso, a su vez, modifica partidas y de acuerdo con los diferentes intereses expresados, sanciona anualmente la ley de Presupuesto. Esto muestra tanto la dimensión técnica (en cuanto a criterios de formulación y seguimiento de resultados de gestión) como el aspecto político que define cuáles son las prioridades anuales que se proponen tanto el Poder Ejecutivo como el Congreso de la Nación.

Más allá de que el ciclo presupuestario tiene un fuerte contenido técnico, también responde a criterios discrecionales o políticos, que se manifiestan en la variación del crédito aprobado de año a año, así como en las posibilidades de contar con ampliaciones y modificaciones o sufrir recortes a lo largo del periodo, producto de decisiones de política económica que en ocasiones llevan a restringir la asignación de recursos, mientras que, en otras circunstancias, da lugar a ampliaciones presupuestarias cuya ejecución no siempre es factible. En un terreno más específico, la definición de techos y sobretechos presupuestarios asigna a las autoridades de los ámbitos en los que se elabora y perfecciona el proyecto de Ley de Presupuesto (Secretaría de Hacienda y Jefatura de Gabinete de Ministros) una capacidad discrecional para definir los montos de recursos asignables. En lo estrictamente referido a los recursos humanos, estos son expresados presupuestariamente a través del inciso 1 del proyecto y de la norma presupuestaria. Asimismo, su presencia puede identificarse en la Cuenta de Ahorro, Inversión y Financiamiento dentro de los Gastos Corrientes en el ítem Remuneraciones. A su vez, dentro de la presentación de la Cuenta de Inversión que elabora la Contaduría General de la Nación se incluye un cuadro anual de Cargos Presupuestados y Cargos Ocupados (relacionado con la Planta Permanente de las Jurisdicciones y de los Organismos). La asignación de cargos presupuestados tiende a ser bastante estricta en cuanto a sus posibilidades de ampliación, aunque las autoridades de las organizaciones suelen negociar ampliaciones con base en las necesidades de cumplimiento de los objetivos organizacionales. Por su parte, debe hacerse referencia a un argumento no desdeñable, de acuerdo al cual, el control centralizado del gasto (en este caso, del Inciso 1) supone poner barreras a decisiones "desenfrenadas" de gasto en las que podrían caer las áreas de gestión.

Durante largos periodos la política presupuestaria estuvo dominada por el déficit estructural y las constantes restricciones al gasto para enfrentar el endeudamiento externo. Estas fuertes restricciones orientaron el conjunto del gasto y en particular en lo referido a la política de recursos humanos. En buena medida, el ciclo concluido en 2001 marca la presencia de una variada muestra de decisiones de naturaleza presupuestaria que incidieron en forma restrictiva en la gestión de los recursos humanos. Como ejemplo, podemos citar los retiros voluntarios, las jubilaciones anticipadas, la existencia de plantas 
de contratados o personal no permanente, el pase de agentes a situación de disponibilidad, los despidos por superposición de estructuras o los despidos directos con o sin indemnización y, finalmente, el congelamiento de vacantes.

Una importante novedad que deparó el proceso abierto a partir de 2003 radica en la expansión presupuestaria y en la mayor capacidad de gasto que se genera para las organizaciones. De acuerdo con la información que surge de las Tablas 2 y 3, en el Apéndice, es visible la caída de la ejecución presupuestaria de 2001 respecto de 2000, aunque puede señalarse que esta situación no es homogénea, ya que, por ejemplo, tanto el gasto en remuneraciones como el gasto de capital tienen caídas mayores que la experimentada por los gastos totales. En la evidente recuperación que se produce posteriormente se observa que el mayor incremento se da en los gastos de capital, que se manifiesta tanto en su significativa variación (comparada con otros conceptos) así como por su peso relativo (duplicando su peso anterior) dando lugar a una verdadera transformación en el paradigma de la ejecución presupuestaria. En un sentido inverso, se observa que las remuneraciones son las que tienen una variación menor de los conceptos presentados y, a su vez, su presencia relativa disminuye respecto de los años 2000 y 2001.

Como se ha mencionado en otro trabajo (Cormick 2009) el gasto en personal permanente funcionaba históricamente como una variable inflexible a la baja, dados los impedimentos normativos para el despido y para la reducción de salarios. Sin embargo, durante el periodo 1989-2002 se aplicaron distintas políticas de reducción de personal (particularmente en 1991, 1996 y 2000) y se produjo una controvertida reducción de salarios (13\% en 2001, a través del Decreto N 926). La combinación de ambos factores dio lugar a la estabilidad de los salarios de la planta permanente del sector público, que en la práctica significó un largo periodo de congelamiento, coherente con un modelo de búsqueda de equilibrio fiscal con base en la contención del gasto público.

De acuerdo con lo que se observa en la Tabla 4 del apéndice, hay periodos en los que cae la masa salarial de la APN. Cabe señalar que esta disminución puede deberse a una combinación de dos factores: reducción del número de agentes públicos y caída del salario. Estos periodos coinciden con la segunda reforma del estado, que supuso la eliminación de una importante cantidad de áreas de gestión, la aplicación de normas de retiro voluntario y la crisis de 2001, que incluyó la reducción salarial de los agentes públicos. Inversamente, a partir de 2003, los valores nominales de las remuneraciones suben de manera consistente. ${ }^{6}$ La misma tabla presenta los porcentajes de variación del personal de la APN de acuerdo a lo que informan la Dirección Nacional de Ocupación y Salarios del Sector Público (DNOSSP) y la Contaduría General de la Nación (CGN). ${ }^{7}$

A este respecto, corresponde precisar algunas cuestiones relacionadas con la homogeneidad de la información sobre el empleo público. Las fuentes (DOSSP y el informe 
de la Cuenta de Inversión realizado por la CGN, ambas en el ámbito de la Secretaría de Hacienda) presentan la información con ciertas diferencias, por lo que es necesario prestar atención más a las tendencias generales de los valores que a su singularidad. ${ }^{8}$ En este punto se puede observar que, en el caso de las remuneraciones globales presentan una caída en 2002 respecto del total de remuneraciones de 1994, a la vez que estos datos (siempre a valores nominales) muestran un significativo crecimiento en 2008 respecto del mismo año 1994. A su vez, la cantidad de puestos ocupados en la APN, en 2008 no alcanzan los valores de 1994. ${ }^{9}$ Ahora bien, si se cruza la información presentada con el Índice de Precios al Consumidor se observa un movimiento relativamente homogéneo entre las variaciones salariales y el IPC hasta 2001. A partir de ese año, los salarios quedan por debajo del IPC y crecen por encima de éste a partir de 2006 y 2007 (Ver Gráfico 1).

Un análisis sectorizado, a partir de la información de la DNOSSP, permite identificar la evolución salarial en el periodo comprendido entre 1997 y 2008. En este caso, se puede observar la significativa heterogeneidad entre diferentes colectivos laborales y se destaca el crecimiento (respecto del IPC) del sector vinculado a convenios colectivos de trabajo del ámbito privado (DGI, Aduana, ANSES y otros) a partir de 2002. A su vez, se observa el retroceso salarial del sector identificado como contratado. Los otros sectores, SINAPA, Entes Reguladores y Personal de Organismos de Ciencia y Tecnología, sin alcanzar los valores del primer sector, mejoran su posición con relación al IPC entre 2005 y 2006 (Véase Gráfico 2).

Así, desde el punto de vista presupuestario, se observan diferencias relevantes entre las políticas aplicadas a partir de 2003 y el periodo comprendido por la década de 1990. En primer lugar, en el marco del convenio colectivo de trabajo, que tuvo un fuerte impulso a partir de 2005, se estableció una política de acuerdos salariales a lo largo de los últimos años, que permitió definir por medio de convenios el valor de los salarios de la APN. En segundo lugar, si bien se mantiene una política de relaciones laborales precarias, que se expandió en la APN durante la década de 1990, la continuidad laboral de estos trabajadores ha sido garantizada por el sostenimiento de recursos presupuestarios en forma sistemática a partir de 2003. Esta decisión está favorecida por el dictado del Decreto 1421 en 2002, reglamentario de la Ley 25164 de Regulación del Empleo Público Nacional. Este decreto, en su Artículo $9^{\circ}$ establece los requisitos para la contratación de agentes bajo el régimen del empleo público en relación de dependencia sin estabilidad. Complementariamente, se produce una sistemática reducción de las contrataciones a través de la locación de servicios, hoy regulada por el Decreto 2345 de 2008. Esto se debe a que la gran mayoría de los trabajadores incluidos en esa modalidad fueron incorporados en el régimen del mencionado decreto 1421. A esto se le agrega el crecimiento de la convocatoria a concursos a partir de 2008, que permitió la obtención de la estabilidad laboral a nuevos trabajadores estatales. 
Debe señalarse, sin embargo, que la planificación presupuestaria ha sido poco flexible ante los requerimientos de ampliación de los techos presupuestarios del inciso 1, en particular en las partidas referidas a las vacantes físicas de planta permanente, lo que ha generado limitaciones a la incorporación de nuevos agentes al empleo permanente. Según se observa en la Tabla 5, el crecimiento de los cargos financiados en la Administración Central de la APN, que incluye los principales colectivos civiles (SINAPA -hoy SINEP- y Personal Civil de las Fuerzas Armadas) y los cargos de las Fuerzas Armadas y de Seguridad tienen un incremento muy leve entre 2001 y 2008.

Abundando sobre los aspectos físicos del presupuesto en recursos humanos, si bien a lo largo de los años se observa un incremento de la planta ocupada, producto, principalmente del crecimiento del personal contratado, al prestar atención específica a las plantas permanentes, particularmente del personal del escalafón SINAPA (hoy SINEP) y del Personal Civil de las Fuerzas Armadas (las más numerosas del personal civil de la APN), la Tabla 6 permite observar un leve pero sistemático retroceso de la planta ocupada a lo largo del periodo. En el caso del SINAPA/SINEP esta caída es del 22\%, mientras que entre el Personal Civil de las Fuerzas Armadas llega al 9 por ciento. Esto indicaría la dificultad en el reemplazo de los agentes que abandonan la función pública, fundamentalmente como resultado del acceso a la jubilación. Este crecimiento a un ritmo relativamente bajo, actúa como un freno presupuestario a la expansión del gasto en planta permanente.

La información anterior lleva a la necesidad de evaluar que, aun existiendo un crecimiento reducido de las vacantes en la APN, no se logra su reposición, y al ser mayor la cantidad de egresos que la de ingresos, esto salda en una disminución neta del personal permanente de ambos colectivos laborales. A lo anterior se suma que la edad de buena parte del personal permanente supera los 50 años.

El importante crecimiento del personal contratado da cuenta de la presencia de elementos presupuestarios y políticos. La significación presupuestaria de este grupo laboral responde al hecho de que el personal contratado no percibe la misma cantidad de suplementos que la planta permanente, lo que lleva a que, en la práctica, su costo laboral sea menor. A la ausencia de estabilidad laboral legal (aunque, como se ha señalado, en los hechos se ha mantenido una significativa estabilidad para este sector) se le suma una condición de menoscabo en sus ingresos respecto de trabajadores permanentes de condiciones profesionales y laborales similares. ${ }^{10}$ Esta restricción actúa como un diferenciador entre trabajadores que asumen responsabilidades equivalentes y se hace más relevante cuando se trata de agentes con formación profesional. Esta circunstancia actúa como un elemento de control del gasto ya que, ese mismo personal, de ser permanente, accedería con relativa facilidad a componentes salariales de los que está excluido el personal contratado. 
El aspecto político, sobre el que se volverá más adelante, toca la cuestión relacionada con la estabilidad laboral y su impacto sobre la fidelidad y compromiso del personal que accede a dicha condición. Crudamente dicho, la perspectiva anclada en el sentido común predica que la adquisición de la estabilidad conspira contra los principios de compromiso y fidelidad laboral Esta visión tiende a convalidar implícitamente las prácticas de informalidad en las relaciones laborales en la administración pública y a desacreditar el clásico principio de la estabilidad del funcionario público. Sin embargo, la carencia de estabilidad estimula la búsqueda de otras alternativas laborales ante el temor a la pérdida del empleo como resultado de los cambios en la gestión de las organizaciones.

La Tabla 7 permite ver de qué manera se ha incrementado la participación de personal contratado en la APN a lo largo de los años, lo que informa sobre la necesidad de la administración de contar con mayor cantidad de agentes para afrontar el conjunto de responsabilidades a su cargo.

Volviendo a lo comentado al inicio del trabajo, cabría preguntar si estas asignaciones de recursos son suficientes para afrontar los crecientes desafios de la administración pública, ya que el proceso de envejecimiento y falta de renovación durante años de la planta permanente de la APN ha estimulado la búsqueda de caminos alternativos para afrontar sus necesidades de recursos humanos. En este sentido, es necesario ampliar la mirada para identificar otras fuentes presupuestarias utilizadas para afrontar gastos relacionados con servicios técnicos y profesionales que no corresponden estrictamente a gastos en personal pero que atienden necesidades de gestión de recursos humanos de las organizaciones. Esta consideración invita a analizar el efectivo papel del presupuesto para identificar los gastos en personal y en qué medida esta restricción es sorteada o relativizada por acciones de las administraciones. ${ }^{11}$

Por otra parte, debe recordarse que desde el punto de vista presupuestario una gran diferencia entre la planta permanente y el personal contratado es que la primera no solo es una dimensión financiera sino también física, mientras que el presupuesto para contrataciones no hace referencia a una unidad física, sino a recursos financieros (no debiendo exceder el 15\% del total de la planta permanente -concepto cuya eficacia cabría verificar-), lo cual facilita la contratación de personal. Si a esto se le agrega la posibilidad de ampliaciones presupuestarias para las partidas de personal contratado durante el ejercicio, se fortalece la idea de mayor flexibilidad al alza de estas partidas.

En resumen, la restricción presupuestaria ha jugado durante varias décadas un rol determinante en las políticas estatales, entre ellas la de recursos humanos, ya que los principios de restricción del gasto definían las decisiones de políticas en este ámbito y neutralizaban decisiones de naturaleza técnica que tomaba el mismo Estado (por ejemplo, el debilitamiento del Cuerpo de Administradores Gubernamentales o la disminución de 
ingresos de personal en la Administración Pública a través de concursos). En los últimos años, esta dimensión dejó de contar como un elemento flexible a la baja, ya que, como se indicó, la mayor parte del gasto en personal permanente y no permanente, tiende a consolidarse y a crecer, particularmente como producto de la política de acuerdos salariales anuales vigente en los últimos años. Así, en la actualidad, aun con ambivalencias, el presupuesto tiende a actuar en forma subordinada a las estrategias de mayor protagonismo del sector público, aunque eso tampoco significa que el Estado haya desarrollado estrategias sistemáticas y permanentes relacionadas con la gestión de recursos humanos.

\section{Restricción política}

Se han presentado hasta aquí restricciones que establecen obligaciones para los responsables de la toma de decisiones en las organizaciones. En un caso, la restricción técnica exige designar agentes que reúnan un determinado perfil profesional que permita el cumplimiento de los objetivos organizacionales o de requerimientos normativos. En el otro caso, las restricciones presupuestarias, intervienen regulando la asignación de recursos presupuestarios, lo que pone límites a la expansión de los gastos en personal de las organizaciones.

Ambas restricciones son de algún modo "objetivas" o externas a las organizaciones, en la medida en que los decisores internos tienen un margen de autonomía acotado para actuar sobre ellas. Sin embargo, cuando a las anteriores dimensiones se le agrega una determinada capacidad interna de decisión en la incorporación de agentes o en la asignación de responsabilidades, se hace presente otra restricción que definiremos como política en cuanto juegan aspectos discrecionales y en cuya determinación intervienen activamente las autoridades de cada organización.

A partir de lo anterior se hablará de restricción política. Por ésta se entenderá el conjunto de decisiones que se toman desde el nivel de conducción de la organización y que, aquí se propone, intentan garantizar mayor poder interno y capacidad de negociación externa a este nivel de decisión, a partir de incorporar recursos humanos adecuados para facilitar el logro de sus objetivos.

La dimensión política se hace presente en forma evidente en la cobertura de aquellas funciones expresamente reservadas como es el caso de los funcionarios superiores o de gabinete. Sin embargo, esto no impide que se efectivice (con mayor o menor formalidad) en la designación de funcionarios para la cobertura de puestos directivos o para la contratación de personal con diversos niveles de responsabilidad.

El caso particular de la designación de funcionarios para el ejercicio de responsabilidades directivas muestra una clara tensión entre la restricción técnica y la política. En el ámbito laboral de la APN regido por el SINEP los cargos directivos deben surgir 
de un concurso abierto en el que las autoridades jurisdiccionales tienen intervención particularmente al momento de proceder a la selección final entre una terna de candidatos. Este procedimiento garantiza una estabilidad de cinco años en el ejercicio de la función. En los últimos años se ha reducido significativamente el número de funcionarios surgidos de ese mecanismo de selección y estas responsabilidades son cubiertas por funcionarios designados de manera transitoria, a solicitud de las autoridades superiores de la organización. Evidentemente, esta modalidad supone un mayor control político sobre el ejercicio de los cargos directivos.

La presencia de la restricción política puede medirse por los procesos de ingreso/egreso de agentes (permanentes y contratados) en la organización, en aquellas situaciones en que dicho proceso no se produzca por razones técnicas. En lo referido al personal de planta permanente, la incorporación a la planta por concurso o el egreso por jubilación manifiestan la presencia de la dimensión técnica. Para los agentes contratados, la dimensión técnica interviene en los casos en que se requiere un perfil con el que hasta ese momento no se cuenta, o en el aumento de la demanda (situación que se ha presentado en ocasiones) o en casos de reemplazo por renuncia espontánea de algún agente y en la que los procesos de selección se realicen con base en principios profesionales (aun sin recurrir a procedimientos formales de selección por concurso). Cuando el reemplazo ocurre por razones diferentes, se señalará que se hace presente la restricción política; por ejemplo, cuando los procesos de reemplazo suponen el egreso e ingreso de agentes de similar perfil, se está ante la intervención de la restricción política, ya que las razones de este reemplazo no radican en factores técnicos ni probablemente presupuestarios. Al indagar sobre el tipo de razones que llevaron a estas decisiones y cómo se evaluaron sus costos y beneficios, es razonable pensar que han intervenido aspectos relacionados con la conducción política, el compromiso con la gestión, el alineamiento con las autoridades, etc.

La intervención de naturaleza política no es privativa de la acción monolítica de las autoridades de una organización sino que es un ámbito en el que se mueven diversos actores (con capacidades y recursos diferentes). En primer lugar, el actor preponderante está constituido por las propias autoridades políticas de la organización (que pueden actuar en forma homogénea o dispersa), en segundo término, debe hacerse referencia a autoridades externas superiores, que pueden hacer valer su decisión para determinadas funciones o solicitar atención a los ocupantes de ciertos puestos laborales. En tercer término hay que hacer referencia a las organizaciones gremiales que incluyen entre sus factores de prestigio la capacidad para gestionar designaciones en diversos niveles (habitualmente en los de menor jerarquía). Asimismo, el personal, desde distintos niveles jerárquicos, genera solicitudes orientadas a la mejora de las condiciones salariales de determinados agentes o a la incorporación de nuevos trabajadores habitualmente vinculados por lazos familiares. Finalmente, y dependiendo de las articulaciones concretas de cada organización, surgen demandas desde el exterior: algunas de la política 
partidaria, otras desde ámbitos corporativos o de clientelas relacionadas con la gestión de la organización.

En este sentido, la capacidad de la organización para procesar estas demandas también podrá dar cuenta del peso de las restricciones técnicas y presupuestarias en el momento de su atención. Así, es factible, que para la atención de este tipo de demanda, se establezcan determinados requisitos que privilegien aspectos técnicos, lo que podrá servir como barrera a demandas de aspirantes a acceder a condiciones de empleo cuyas calificaciones laborales no son compatibles con las perseguidas por la organización. El Cuadro 2, en el Apéndice, presenta sintéticamente estas opciones.

Para concluir este apartado, cabe recordar la clásica formulación de Oscar Oszlak en "Notas críticas para una teoría de la burocracia estatal" (1984:285) en la que da cuenta del triple rol de la burocracia: sectorial relacionado con la defensa de intereses propios, concepto vinculado a la tradicional visión de la "desviación de objetivos"; mediador, como expresión de intereses de las clases dominantes, que refiere a la también histórica perspectiva de que la burocracia estatal no es más que la expresión de los intereses de las clases dominantes, e infraestructural que supone la atención de intereses generales, en el sentido que el Estado y su burocracia son un actor neutral que atiende técnicamente tales intereses. Esta definición da cuenta de la presencia de aspectos no solo técnicos en la acción burocrática sino una fuerte presencia de rasgos corporativos e ideológicos.

\section{Consideraciones finales}

En este trabajo se ha tratado de mostrar la intervención de diversas dimensiones, entendidas como restricciones, en la configuración de la gestión de los recursos humanos en las organizaciones públicas, las que corresponden al nivel técnico, al nivel presupuestario y al nivel político, formando parte, como se ha señalado, de un debate, sobre cuál debe ser la restricción que determine los desarrollos de los recursos humanos en el ámbito público. El nivel técnico parte de ser reconocido desde el sentido común como el único legítimo para definir una política de recursos humanos en las organizaciones estatales y se expresa claramente a través de los sistemas de selección basados en el mérito y en la presencia de perfiles profesionales para la cobertura de puestos laborales que requieren determinada especialización.

La dimensión presupuestaria, como ya se mencionara, es la menos identificada en los debates al respecto, aunque, como se señalaba en páginas anteriores, su presencia en determinados periodos ha sido central y previa a las determinaciones de carácter técnico y de carácter político, subordinando estos campos a las decisiones relacionadas con la asignación de recursos. El predominio de la dimensión presupuestaria da cuenta de la sobrevivencia de una perspectiva que identifica al empleo público como una innecesaria carga sobre los contribuyentes que debería ser disminuida. 
Por otra parte, la dimensión de carácter político, podría decirse que es valorada en forma negativa y considerada como un obstáculo para el adecuado desempeño de las organizaciones. Sin embargo su presencia se relaciona con la congruencia entre los objetivos perseguidos por las organizaciones (y finalmente, por las autoridades electas por la ciudadanía) y el perfil de los recursos humanos aplicados a su concreción.

Tanto la creación del Cuerpo de Administradores Gubernamentales como del Sistema Nacional de la Profesión Administrativa (SINAPA) implicaban un fortalecimiento de la restricción técnica, en cuanto privilegiaban el concepto de adaptar el modelo de reclutamiento y desarrollo de los recursos humanos al cumplimiento de responsabilidades relacionadas con el logro de los objetivos de las organizaciones públicas. Sin embargo, ambos proyectos han quedado relativizados en su alcance y buena parte de las decisiones que limitaron estas iniciativas radicaron en la subordinación genérica de la mayor parte de las políticas estatales a las necesidades del ajuste fiscal.

Las tendencias en gestión de recursos humanos, caracterizadas por el congelamiento de vacantes, bajo nivel de cobertura de vacantes por concurso, utilización sistemática de personal contratado, uso de otras fuentes de incorporación de personal, marcan la preeminencia global de la restricción presupuestaria, mientras que la variable política se hace más presente en las modalidades menos formalizadas de cobertura. Sin embargo, esta situación puede expresar tendencias "técnicas" no resueltas por mecanismos formales y que son atendidas a través de sistemas precarios de reclutamiento y contratación. La restricción política interviene en las acciones que han limitado en distintas épocas el éxito de las estrategias innovadoras de carácter técnico. Por ejemplo, la escasa propensión a fortalecer el perfil profesional del SINAPA pudo ser coincidente con valores e intereses políticos relacionados con el tipo de perfil laboral a favorecer en la organización del empleo público. Siguiendo las ideas propuestas por Klingner y Nalbandian (2001) podría identificarse como relaciones de patrocinio que son sostenidas a través de estructuras escalafonarias de baja profesionalidad.

La proliferación de escalafones en la APN también puede señalarse como una manifestación de la dimensión política, en el entendimiento de que su amplia diversidad, no expresa especificidades técnicas significativas. Una consecuencia previsible de esta diversidad es la heterogeneidad o dispersión salarial en la APN, como se observa en el Gráfico 2.

Esta observación lleva a diferenciar dos aspectos relacionados con la heterogeneidad de las organizaciones públicas, para lo que debe prestarse atención a la diferencia existente entre lo que se definirá como "heterogeneidad técnica" y "heterogeneidad política". Mientras la primera refiere a las especificidades propias de cada organización, que se vinculan con los objetivos perseguidos y obligan a una determinada forma de organi- 
zación de sus recursos humanos, la heterogeneidad política da cuenta de los acuerdos o decisiones establecidos por los distintos actores institucionales que generan modalidades particulares de gestión de los recursos humanos que no necesariamente se corresponden con los objetivos técnicos de la organización.

De esa manera, los diferentes intentos por estandarizar u homogeneizar la gestión de recursos humanos no han logrado cristalizar como experiencias exitosas o generalizadas. En buena medida, esto estaría señalando la mayor eficacia relativa del proceso de desmantelamiento del estado "intervencionista" en la primera mitad de la década del noventa que la de los sucesivos intentos de reconstrucción iniciados posteriormente. También estaría dando cuenta de las dificultades que enfrentan las estrategias de homogeneización que, en ocasiones proponen una visión uniformizada de la organización y gestión de los recursos humanos, dejando de lado las especificidades técnicas de las diferentes organizaciones. No habría que omitir un cierto nivel de corporativización que se ha constituido en las organizaciones públicas y que restringe la realización de transformaciones que pueden afectar intereses particularistas no necesariamente consistentes con la función del sector público como expresión del interés general de la sociedad.

Dos estrategias de los años recientes indican una tendencia interesante a fortalecer, en la medida que buscarían articular las tres dimensiones bajo estudio. En primer lugar, la instauración y posterior ampliación del alcance del Convenio Colectivo de Trabajo para la APN, que cristalizó en el Decreto 214/06 y que contó con la firma de los dos principales sindicatos que representan a los trabajadores de la APN, ATE y UPCN. El proceso de inclusión de una gran cantidad de sectores laborales (y escalafones) avanza en la mencionada homogeneización de la APN, ya que se sostienen principios ordenadores generales y se respetan las particularidades de cada sector laboral, que deberá expresarse en los respectivos convenios sectoriales. A su vez, su cumplimiento exige la atención a las condiciones presupuestarias existentes, al tiempo que, como se señalaba, la participación de las dos entidades gremiales signatarias como firmantes del convenio confiere consistencia política al acuerdo.

En segundo lugar, el convenio sectorial de la APN, expresado en el cambio del SINAPA por el Sistema Nacional de Empleo Público (SINEP), supone también varias novedades, entre las que se destaca la creación del agrupamiento profesional y la mayor diversidad en las opciones de la carrera individual, expresada en la figura de los tramos y en la ampliación de grados en virtud de la antigüedad de los agentes que supera los grados previstos originariamente. Queda por ver si estos agrupamientos son suficientemente inclusivos de los requerimientos laborales de la APN, particularmente para aquellos que se alejan de las típicas funciones administrativas o profesionales. Por otra parte, uno de los aspectos que debilitó al SINAPA fue la escasa movilidad vertical (lo que muestra otra forma de presencia de la restricción presupuestaria). La atención de esta problemática en el SINEP evitaría el riesgo del congelamiento del sistema. 
Respecto del personal contratado debe considerarse un aspecto que atañe a toda la APN (e, incluso, al conjunto del Sector Público Argentino). La contratación de personal, al ser un mecanismo apto para sortear restricciones originadas en las políticas de contención del gasto (congelamiento de vacantes) y al reducir los gastos en personal, se ha transformado en una modalidad de relación laboral muy extendida (que contraviene el principio general de la eventualidad de la contratación). Las consecuencias de no atender esta problemática son de dos órdenes: a) posibilidad de judicialización del vínculo y de sanción al Estado debido a que establece relaciones laborales precarias encubiertas en modalidades contractuales no laborales, y b) debilidad para conformar una planta laboral sólida. El cuadro 3 propone una mirada esquemática sobre las ventajas y dificultades que surgen del predominio de alguna de las variables en juego.

Puede señalarse que la asignación de recursos humanos en puestos clave basada en la restricción política privilegia el concepto de confianza y compromiso por encima del de independencia de criterio, aunque esta gravitación de la confianza, que provee seguridad a la autoridad en la toma de decisiones, puede generar respuestas más acomodadas a las necesidades particulares de esta autoridad, con la consiguiente pérdida del perfil técnico de sus intervenciones.

Sin embargo, puede dar lugar a que las autoridades eludan el vínculo con los trabajadores estables, lo que produce un mayor distanciamiento entre las autoridades y los agentes públicos con la consiguiente falta de involucramiento de dicho personal en los objetivos organizacionales y la despreocupación de las autoridades en la formación técnico profesional de estos trabajadores.

Sería erróneo suponer que los efectos de aplicar mecanismos de contratación son unilateralmente negativos. Además de la mencionada (y no de menor importancia) flexibilidad presupuestaria, y de la previsible confianza en los resultados que pueden ser alcanzados en la medida que estos agentes adhieren a los objetivos de las autoridades, también el decisor político cuenta con un conjunto de recursos renovables que puede ser aplicado como elemento de negociación, particularmente con actores externos. Pese a no ignorar estas eventuales ventajas, quedan en pie los costos institucionales más generales de estas prácticas.

En el marco de las transformaciones ocurridas en la década de 1990 las administraciones públicas tendieron a incorporar el modelo de la Nueva Gestión Pública (NGP) cuyos principios están constituidos por las denominadas "CincoR": "Reestructuración”, "Reingeniería”, "Reinvención”, "Realineación” y "Reconceptualización” (López s/f:10-11) lo que supone entre otros aspectos una caracterización del perfil de los recursos humanos orientado por principios empresariales. Al decir de Miguel Sánchez Morón (2007:11) 
una administración moderna ... que se responsabiliza de la creación y prestación de una pluralidad de servicios, que debe responder a las demandas sociales con eficacia y eficiencia crecientes, y que basa, por ello, una buena parte de su actuación en una lógica empresarial, necesita disponer de directivos cualificados.

Esto llevó a un rico debate expresado por una parte por el documento del CLAD, Una Nueva Gestión Pública para América Latina (1998), que ofrece una interesante visión, tomando aspectos de la perspectiva de la Nueva Gestión Pública, en cuanto a las cualidades que debe reunir un gerente público, al que se le reclamarán resultados de gestión, por lo que se espera que actúe con autonomía para poder responder por tales resultados. Esta búsqueda de la autonomía en buena medida supone la presencia de la dimensión política, ya que implica gozar de capacidad discrecional relacionada con el logro de los objetivos que persigue la organización. Prats y Catalá (2001), por su parte, sostiene que la propuesta de incorporar los principios de la NGP se debe limitar a las agencias relacionadas con la prestación de servicios (que pueden definir objetivos y resultados claramente mensurables) mientras que no sería aplicable al núcleo de la administración pública, el que, al decir del autor, debería ser reconstruido con base en los principios weberianos.

La aplicación de los principios de la NGP ha generado algunas miradas orientadas a revisar sus efectos, no siempre semejantes a los esperados. Así, Tom Christensen y Per Lægreid (2007:587) manifiestan su preocupación por el ensilamiento que produce entre y dentro de las organizaciones la aplicación de los principios de evaluación, control de resultados, etc., y afirman que

El desempeño de gestión motiva a las personas y a las organizaciones a cumplir con sus propias metas de desempeño y hay una tendencia hacia un poco de segmentación de las formas organizacionales. En contraste TG [Totalidad de Gobierno] intenta promover cooperación, redes y colaboración entre organizaciones.

A su vez, Peter Evans (2007:80) expresa su preocupación por el peso de los mecanismos de mercado en las decisiones públicas y propone el modelo trípode de Administración (Pública) en el que integra la capacidad burocrática, la respuesta a las señales del mercado e incorpora el concepto de control democrático (vid Figura 1 en el Apéndice). Francisco Longo (2004: 71,72) interviene críticamente respecto de la presencia de la política en la gestión de recursos humanos en las administraciones públicas. A este respecto, hace mención a un texto de Prats (1995) según el cual la función pública 
aparece como una creación evolutiva del constitucionalismo moderno, fuertemente asociado al orden liberal del mercado, ya que se trata de una institución clave del valor económico y social fundamental que es la seguridad jurídica, por lo que es un dato observable en todas las economías de mercado exitosas, y en ninguna de las economías planificadas o de sustitución de importaciones, con independencia de la naturaleza autoritaria o democrática de unas $u$ otras.

Esta afirmación supone una perspectiva excluyente sobre la primacía del orden liberal de mercado como único camino legítimo de ordenamiento social, en el que la función pública sólo será genuina de establecerse en ese contexto. En esa misma línea se limita el ámbito de intervención de la política al menor número posible de posiciones, restringidas al nivel más alto de la organización. Esta última formulación probablemente sea eficaz en aquellas administraciones públicas en las que la agenda estatal esté relativamente consolidada y no existan debates en el seno de la sociedad y del Estado en torno a la legitimidad de las agendas y del rumbo que debe seguir la sociedad.

Sin embargo, en la región latinoamericana, se ha reactivado la discusión sobre los modelos de intervención estatal, sobre las características de estas intervenciones y sobre la necesidad de promover procesos de transformación a partir de la acción del Estado. En esa línea se ha producido un quiebre importante respecto de los postulados dominantes en la década de 1990 en un conjunto vasto de temas, entre los que destacan la recuperación o nacionalización originaria de servicios públicos, la reestatización de los sistemas de jubilación privada, la fijación de sistemas de ingreso universal para la niñez, el sostenimiento de la fortaleza fiscal, como resguardo ante las crisis externas, el crecimiento significativo de la inversión pública en infraestructura, la defensa del empleo, la creación de fuertes programas de lucha contra la pobreza, la ampliación de las ofertas públicas en salud y educación, etc., todas acciones que suponen la intervención protagónica de los estados.

Como ejemplo de lo anterior, en el caso argentino se ha desarrollado un intenso debate en torno al concepto de "independencia” del Banco Central de la República Argentina. Éste es, probablemente, un elemento clarificador de la problemática que se está analizando. Una mirada ingenuamente técnica supone que solo el perfil profesional (sustentado en titulaciones internacionales) es suficiente para ejercer dichas responsabilidades. En la medida en que se discute el sentido de la gestión de las organizaciones (no meramente su faz técnica) como parte de un debate más amplio sobre el rol del Estado en particular ante las crisis del sistema financiero internacional, cobra relevancia la dimensión política entendida como la incorporación de una determinada cosmovisión sobre la direccionalidad global de la sociedad y las políticas que deben aplicarse para su alcance. 
Lo anterior supone que la dimensión política no es un elemento meramente residual de la gestión que debe ser arrinconado y limitado a sus menores expresiones, sino que forma parte central de la orientación de la gestión.

A estos efectos es importante citar la reflexión de Guillermo Schweinheim (2011:19) acerca de los desafios actuales de gestión de recursos humanos en la región:

Si es correcta la hipótesis de que para desplegar una administración para el desarrollo en América Latina se requiere consolidar los núcleos operativos, las líneas medias y las tecnoestructuras de una burocracia con una diferenciación departamental y funcional distinta, acorde con los nuevos asuntos del desarrollo y sistemas administrativos y de gestión más modernos, entonces la correlación con la institucionalización del servicio civil es muy alta. Del mismo modo, la implantación de nuevos sistemas de planificación nacional para el desarrollo ( $y$ su función de orientación para la toma de decisiones de las organizaciones estatales $y$ de los actores políticos, económicos y sociales) solo será posible con la presencia de una tecnoburocracia de mérito que participe en la formulación y ejecución del planeamiento de las políticas para el desarrollo".

A partir de lo anterior surgen algunas preguntas, que merecerían atención de parte de quienes conducen la política de recursos humanos en la APN:

- ¿Qué confianza genera en las administraciones públicas la formación técnica brindada en instituciones internacionales que propician visiones antagónicas a las sustentadas por los estados en pro del desarrollo regional?

- ¿Qué calidad de formación en la problemática pública puede esperarse de los profesionales, en la medida que la mayor parte de las grandes universidades contempla escasamente esta problemática en sus carreras de grado? Aunque esta tendencia está buscando revertirse en las universidades creadas en los últimos años.

- ¿Qué estrategias deberían generarse para promover el mayor compromiso de los agentes técnicamente capacitados en los objetivos que persigue la gestión? ¿cuáles son los límites entre estas perspectivas y un vulgar adoctrinamiento?

- ¿cuáles son las competencias laborales a fortalecer en el desarrollo del personal público y cómo podrán plantearse estrategias de formación que permitan identificar la genuina incorporación de estas competencias? ${ }^{12}$ 
Los continuos cambios de orientación política en la gestión de la APN han llevado hasta el presente a la ausencia de una visión de largo plazo respecto de los objetivos de la administración pública. La construcción de una visión de largo plazo y el desarrollo de estrategias institucionales de capacitación que surjan de identificar los principales requerimientos de competencias laborales en el marco de los objetivos de transformación del rol del estado es uno de los caminos necesarios para romper estos círculos de manera virtuosa.

${ }^{1}$ Klingner, Donald E. y John Nalbandian $(2001: 20)$. De acuerdo con estos autores “...el sistema de botín
político ... recompensaba a los miembros del partido y a los trabajadores en la campaña con cargos públicos
al elegir sus candidatos. ... Después de repartir dichos puestos, se verificaba la lealtad al partido ... y en agra-
decimiento el nuevo empleado pagaba al partido una mesada 'voluntaria', la cual se utilizaba para remunerar a
los agentes del partido que le habían obsequiado el puesto y para subvencionar futuras campañas electorales."
${ }^{2}$ Longo, Francisco. $(2004,2006)$ Oszlak, Oscar $(2001)$ Prats, Joan (1995). Ramió Matas, Carles. (2006).
${ }^{3}$ Oszlak (1980) ofrece un interesante análisis sobre estas diferencias organizacionales.
${ }^{4}$ Ley 24185 , artículos $4^{\circ}$ inc. b y $6^{\circ}$; Ley 25164 , artículo $8^{\circ}$, Decreto 1421 de 2002 , artículo $8^{\circ}$ y Decreto 214
de 2006 , artículo 11 , inciso b). Una reciente norma dictada por el Congreso Nacional extiende este requisito al Poder Judicial.

${ }^{5}$ En Cormick (2009), se analizó la presencia de esta dimensión en organizaciones específicas: Auditoría General de la Nación (AGN) y Administración Federal de Ingresos Públicos (AFIP). En ambos casos se observó una fuerte presencia técnico profesional en su personal.

${ }^{6}$ Si se cruza la cantidad de cargos ocupados (permanentes y no permanentes) con base en la información de la Dirección Nacional de Ocupación y Salarios del Sector Público y de la Contaduría General de la Nación, con las remuneraciones realizadas en el periodo comprendido entre 1994 y 2007 y se comparan estos datos con la evolución del Índice de Precios en el mismo periodo se observa que en el periodo 1994-2001, esta relación era estable con leve prevalencia de los haberes, mientras que en el subperiodo posterior, esta relación se invierte con mayor incremento del IPC, y un posterior mayor peso de los haberes en 2007.

${ }^{7}$ http://www.mecon.gov.ar/onp/html/ejectexto/bole_trim_dosuno.html (1997-2008)

http://www.mecon.gov.ar/hacienda/cgn/cuenta/ (1994-2007)

${ }^{8}$ En un trabajo de investigación presentado en la Universidad Nacional de Moreno (Cormick y otros, 2012) se exploró sobre las diversas fuentes de información sobre el empleo público, tratando de identificar las razones que dan lugar a los distintos resultados tanto en valores físicos como los correspondientes a remuneraciones. ${ }^{9}$ Cabe destacar que la información brindada por la DNOSSP discrimina claramente entre personal permanente y personal contratado y deja explícita la presencia de los contratados bajo el régimen del Decreto 1421 de 2002, reglamentario de la Ley 25164 de Regulación del Empleo Público.

${ }^{10}$ En el caso del SINEP, entre los componentes salariales a los que no acceden los agentes contratados, podemos indicar el agrupamiento profesional y el suplemento por actividad específica.

${ }^{11}$ Como ejemplo, el Decreto 92/95 buscó ubicar las cada vez más abundantes locaciones de servicios en el Inciso 1 ya que hasta ese momento se encontraban "ocultas" en el Inciso 3. En la actualidad, las contrataciones de asistencia técnica a universidades no se computan como gastos de personal.

${ }^{12}$ El Consejo Federal de la Función Pública, que incluye a todos los funcionarios provinciales responsables de las políticas de recursos humanos de las administraciones provinciales ha sintetizado una perspectiva integradora del concepto de competencias aplicable al sector público. De ahí se identifican tres bloques de competencias aplicables a la gestión pública.

1. Competencias ético institucionales: referidas a la asunción y expresión de valores compatibles con la vida democrática y el trabajo en instituciones públicas.

2. Competencias técnico profesionales, referidas al conocimiento de la materia propia de los programas que lleva adelante una organización.

3. Competencias actitudinales, referidas a las aptitudes para la organización del trabajo y el tiempo, la resolución de problemas y la toma de decisiones, la comunicación, la mediación y resolución de conflictos, y la integración y conducción de equipos. 


\begin{tabular}{|c|c|c|c|c|}
\hline & 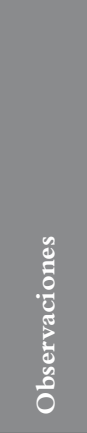 & 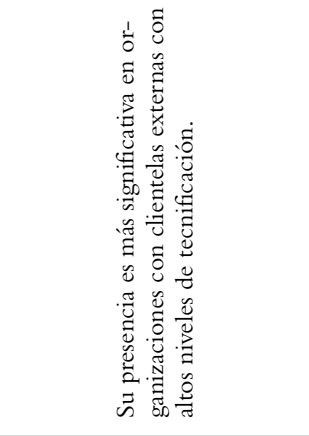 & 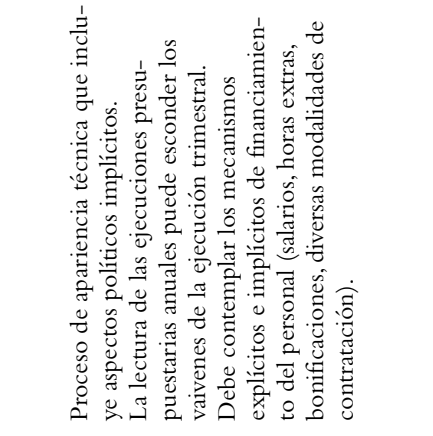 & 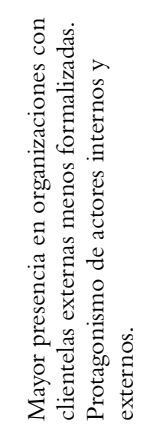 \\
\hline & 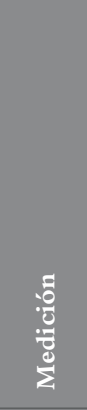 & 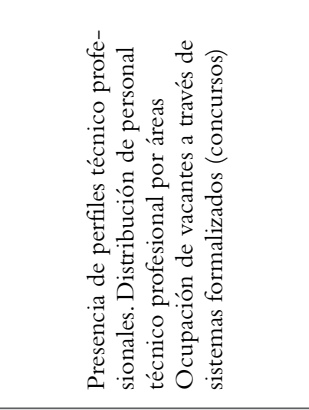 & 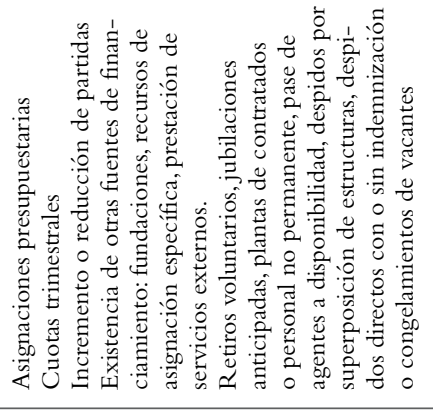 & 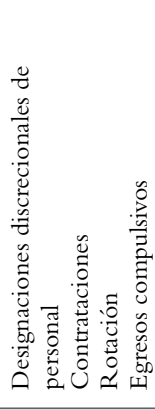 \\
\hline$\frac{J}{b}$ & 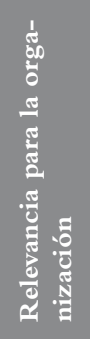 & 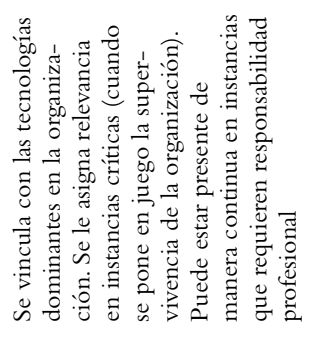 & 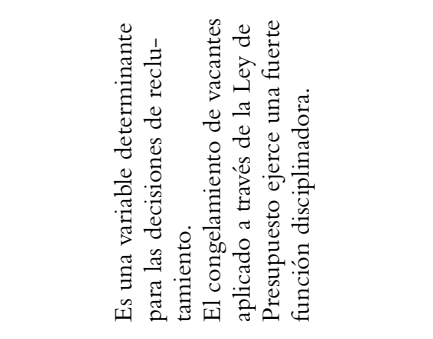 & 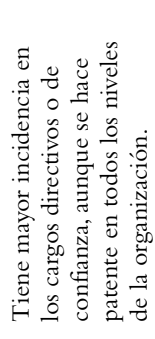 \\
\hline 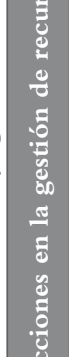 & 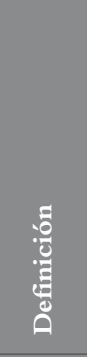 & 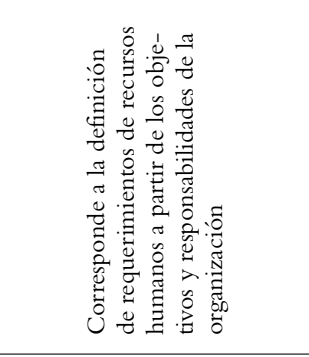 & 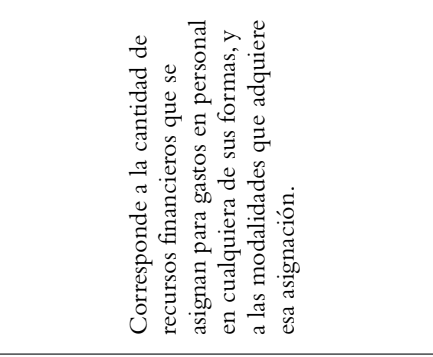 & 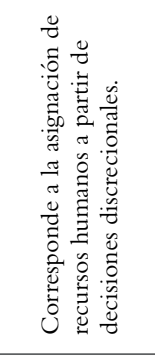 \\
\hline 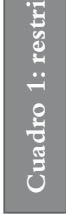 & 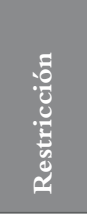 & 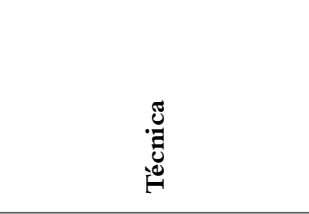 & 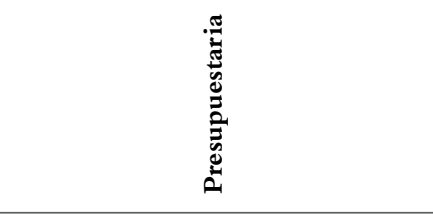 & 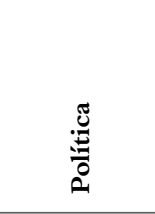 \\
\hline
\end{tabular}




\section{Tabla 1}

APN. Población SINAPA y contratada por decreto 1421 según niveles de estudio

\begin{tabular}{|c|c|c|c|c|}
\hline \multirow[b]{2}{*}{ Nivel de Estudios } & \multicolumn{2}{|c|}{$\begin{array}{l}\text { Población del SINAPA por } \\
\text { Nivel de Estudios (2005) }\end{array}$} & \multicolumn{2}{|c|}{$\begin{array}{l}\text { Personal Contratado Decreto } \\
\text { 1421/02 por Nivel de Estudios } \\
(2007)\end{array}$} \\
\hline & $\begin{array}{l}\text { En cantidad } \\
\text { de agentes }\end{array}$ & En porcentaje & $\begin{array}{l}\text { En cantidad } \\
\text { de agentes }\end{array}$ & En porcentaje \\
\hline Total & 21960 & 100,00 & 19480 & 100,00 \\
\hline Sin estudios & 51 & 0,23 & & \\
\hline Primario & 6566 & 29,90 & 2426 & 12,45 \\
\hline Secundario & 7861 & 35,80 & 9466 & 48,59 \\
\hline Terciario & 1394 & 6,35 & 1668 & 8,56 \\
\hline Universitario & 5777 & 26,31 & 5920 & 30,39 \\
\hline Postgrado & 311 & 1,42 & $\mathrm{~s} / \mathrm{d}$ & \\
\hline \multicolumn{5}{|c|}{$\begin{array}{l}\text { Fuente: SGP. "Boletín Estadístico del Personal del Sistema Nacional de la Profesión Administrativa } \\
\text { (SINAPA). Decreto N }{ }^{\circ} \text { 993/91 (t.o. 1995). Informe de Situación al } 31 \text { de diciembre de 2005." "Algunas } \\
\text { características significativas de las personas contratadas por la Administración Pública Nacional bajo el } \\
\text { régimen del Decreto N¹421/02 durante el año 2007." }\end{array}$} \\
\hline
\end{tabular}

\section{Tabla 2}

Ejecución presupuestaria en años seleccionados. En porcentajes

\begin{tabular}{|l|l|l|l|l|l|}
\hline Año & Gasto total & $\begin{array}{l}\text { Gasto } \\
\text { consumo }\end{array}$ & Remuneraciones & $\begin{array}{l}\text { Gasto } \\
\text { capital }\end{array}$ & Prestaciones ss \\
\hline 2000 & 100 & 19 & 15 & 6 & 36 \\
\hline 2001 & 100 & 18 & 14 & 5 & 35 \\
\hline 2008 & 100 & 14 & 10 & 12 & 33 \\
\hline
\end{tabular}

Fuente: elaboración propia con base en datos de la Secretaría de Hacienda, Oficina Nacional de Presupuesto (http://www.mecon.gov.ar/onp/html/resultado/caja/)

\section{Tabla 3}

Ejecución presupuestaria en años seleccionados. Variación porcentual

\begin{tabular}{|l|l|l|l|l|l|}
\hline Periodo & $\begin{array}{l}\text { Gasto } \\
\text { Total }\end{array}$ & Gasto Consumo & Remuneraciones & Gasto Capital & $\begin{array}{l}\text { Prestaciones } \\
\text { Ss }\end{array}$ \\
\hline $2001 / 2000$ & -3 & -8 & -9 & -18 & -4 \\
\hline $2008 / 2001$ & 303 & 219 & 202 & 848 & 282 \\
\hline
\end{tabular}

Fuente: elaboración propia con base en datos de la Secretaría de Hacienda, Oficina Nacional de Presupuesto (http://www.mecon.gov.ar/onp/html/resultado/caja/) 


\section{Tabla 4}

Administración Pública Nacional

Variaciones porcentuales 2008/1994

\begin{tabular}{|c|c|c|c|}
\hline \multirow{2}{*}{ Periodo } & Remuneraciones del personal & \multicolumn{2}{|c|}{ Cargos ocupados } \\
\cline { 2 - 4 } & Cuenta AIF & DNOSSP & CGN \\
\hline $1995-94$ & 9,14 & & $-3,96$ \\
\hline $1996-95$ & 0,69 & & 11,00 \\
\hline $1997-96$ & $-3,29$ & & $-6,13$ \\
\hline $1998-97$ & $-2,74$ & 2,52 & $-4,83$ \\
\hline $1999-98$ & 5,43 & $-3,36$ & 1,99 \\
\hline $2000-1999$ & 0,79 & 0,34 & $-2,03$ \\
\hline $2001-00$ & $-9,43$ & $-3,05$ & $-1,11$ \\
\hline $2002-01$ & $-6,45$ & 0,75 & $-6,05$ \\
\hline $2003-02$ & 21,57 & 1,27 & 0,06 \\
\hline $2004-03$ & 4,97 & 4,93 & 0,73 \\
\hline $2005-04$ & 20,52 & 2,18 & 3,10 \\
\hline $2006-05$ & 23,75 & 3,87 & 1,67 \\
\hline $2007-06$ & 28,36 & 3,92 & 2,40 \\
\hline $2008-07$ & 32,02 & 2,58 \\
\hline Fuente: Elaboración propia con base en datos SHN (Cuenta AIF, CGN, DNOSSP). \\
\hline
\end{tabular}

\section{Grafico 1:Variación de remuneraciones e Indice de precios 1994-2007} (1997=100)

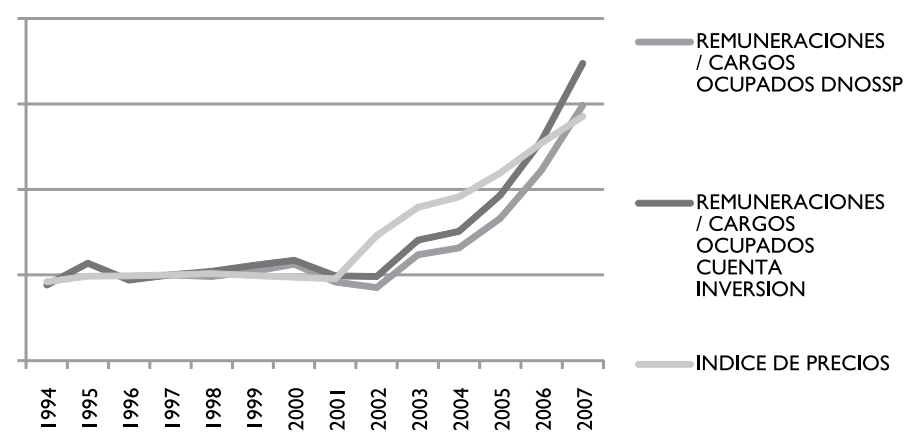

Fuente: elaboración propia sobre datos de DNOSSP y CGN. Secretaría de Hacienda e INDEC: Serie histórica del Índice de Precios al Consumidor (IPC) en el Gran Buenos Aires. Nivel general y capítulos de la canasta. Empalme de las Series Base 1943,1960,1974, 1988 y 1999 con la Serie Base abril 2008=100 
Gráfico 2. Relación salarios y evolución IPC 1997-2008 (1997=100)

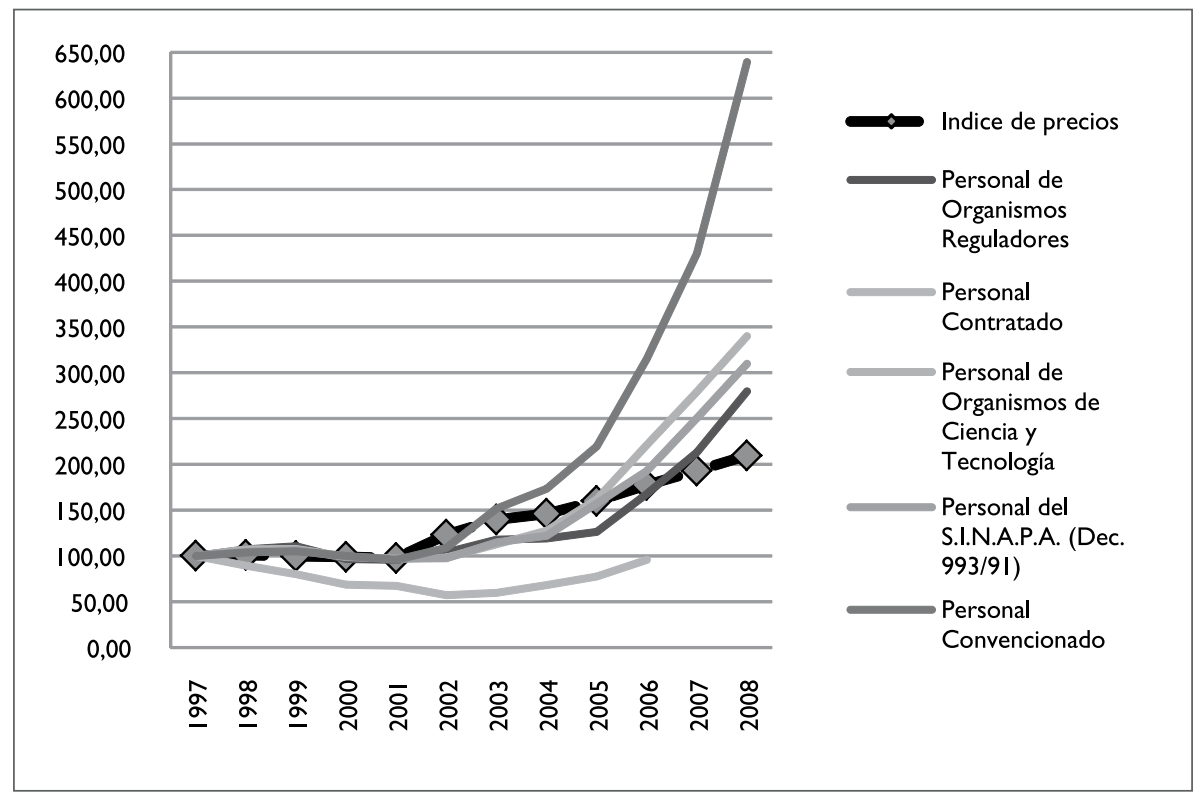

Fuente: elaboración propia sobre datos de DNOSSP. Secretaría de Hacienda e INDEC: Serie histórica del Índice de Precios al Consumidor (IPC) en el Gran Buenos Aires. Nivel general y capítulos de la canasta. Empalme de las Series Base 1943, 1960,1974, 1988 y 1999 con la Serie Base abril 2008=100

\section{Tabla 5}

\section{Administración Pública Nacional}

Vacantes Planta Permanente Administración Central

\begin{tabular}{|l|c|c|}
\hline Año & Total Vacantes Financiadas & $\begin{array}{c}\text { Variación } \\
\text { Porcentual }\end{array}$ \\
\hline 2001 & 219840 & 0,88 \\
\hline 2002 & 221781 & 0,38 \\
\hline 2003 & 222633 & 0,86 \\
\hline 2004 & 224554 & 5,72 \\
\hline 2005 & 237406 & 1,82 \\
\hline 2006 & 241724 & 1,83 \\
\hline 2007 & 246151 & 2,04 \\
\hline 2008 & 251164 & \\
\hline Fuente: Elaboración propia con base en datos SHN \\
\hline
\end{tabular}




\section{Tabla 6}

Administración Pública Nacional

Planta permanente cargos ocupados

\begin{tabular}{|l|l|l|l|l|}
\hline & \multicolumn{2}{l}{ Sinapa } & \multicolumn{2}{l|}{ Personal civil F.A. } \\
\hline Año & Total agentes & $\begin{array}{l}\text { Variación } \\
\text { porcentual }\end{array}$ & Total agentes & $\begin{array}{l}\text { Variación } \\
\text { porcentual }\end{array}$ \\
\hline 1999 & 27606 & & 22947 & \\
\hline 2000 & 26319 & $-4,66$ & 21957 & $-4,31$ \\
\hline 2001 & 25410 & $-3,45$ & 21440 & $-2,35$ \\
\hline 2002 & 24718 & $-2,72$ & 21048 & $-1,83$ \\
\hline 2003 & 24227 & $-1,99$ & 20572 & $-2,26$ \\
\hline 2004 & 24225 & $-0,01$ & 20082 & $-2,38$ \\
\hline 2005 & 23921 & $-1,25$ & 19859 & $-1,11$ \\
\hline 2006 & 23425 & $-2,07$ & 19653 & $-1,04$ \\
\hline 2007 & 21048 & $-10,15$ & 20357 & 3,58 \\
\hline 2008 & 21342 & 1,40 & 20824 & 2,29 \\
\hline \multicolumn{5}{|l}{ Fuente: Elaboración propia con base en datos SHN } \\
\hline
\end{tabular}

\begin{tabular}{|c|c|c|c|}
\hline \multicolumn{4}{|l|}{ Tabla 7} \\
\hline \multicolumn{4}{|c|}{ Administración Pública Nacional } \\
\hline \multicolumn{4}{|c|}{ Personal contratado } \\
\hline \multicolumn{4}{|c|}{ Cargos ocupados } \\
\hline \multirow[b]{2}{*}{ Año } & \multirow{2}{*}{$\begin{array}{c}\text { PEN y Otros Entes } \\
\text { del Sector Público } \\
\text { Nacional No Financiero }\end{array}$} & \multicolumn{2}{|c|}{ PEN } \\
\hline & & Decreto $1184 / 01$ & Decreto $1421 / 02$ \\
\hline 2002 & 16513 & 14.555 & 90 \\
\hline 2003 & 17807 & 14.880 & 256 \\
\hline 2004 & 18900 & 16.505 & 2.829 \\
\hline 2005 & 22491 & 14.694 & 10.686 \\
\hline 2006 & 26742 & 4.946 & 13.275 \\
\hline 2007 & 32043 & 4.485 & 19.837 \\
\hline 2008 & 36187 & 2.775 & 26.037 \\
\hline
\end{tabular}




\begin{tabular}{|c|l|}
\hline Cuadro 2 \\
\hline \multicolumn{2}{|c|}{ Dimensión política } \\
\hline \multicolumn{1}{|c|}{ Actores } \\
\hline Dentro del aparato del estado & \multicolumn{1}{c|}{ Fuera del aparato del estado } \\
\hline Autoridades políticas de la organización & Política partidaria \\
\hline Autoridades externas superiores & $\begin{array}{l}\text { Ámbitos corporativos, profesionales, organizaciones } \\
\text { sociales }\end{array}$ \\
\hline Organizaciones gremiales & $\begin{array}{l}\text { Clientelas relacionadas con la gestión de la } \\
\text { organización. }\end{array}$ \\
\hline El personal de la organización & \\
\hline
\end{tabular}

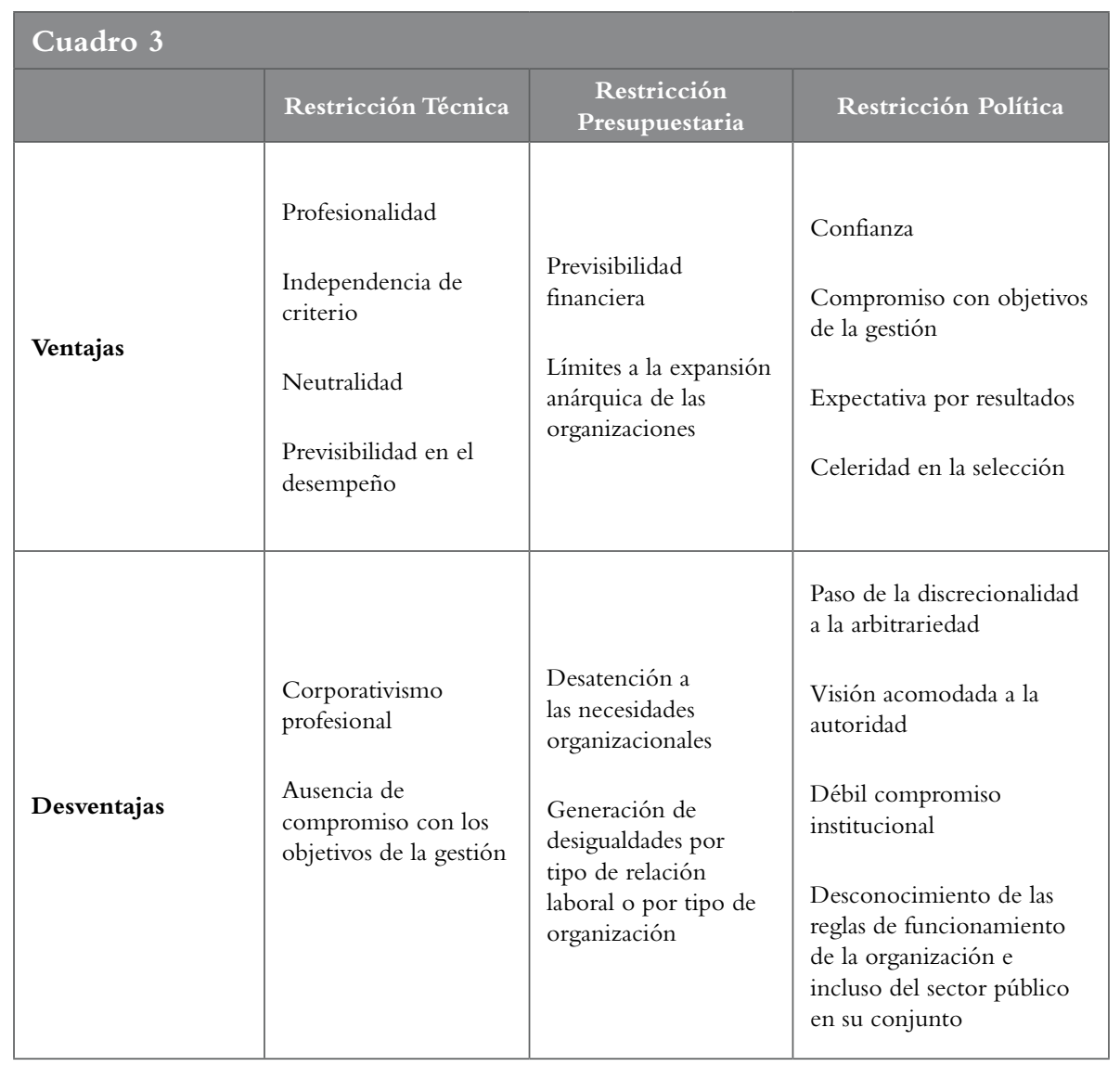


Figura 1: El modelo trípode de administración

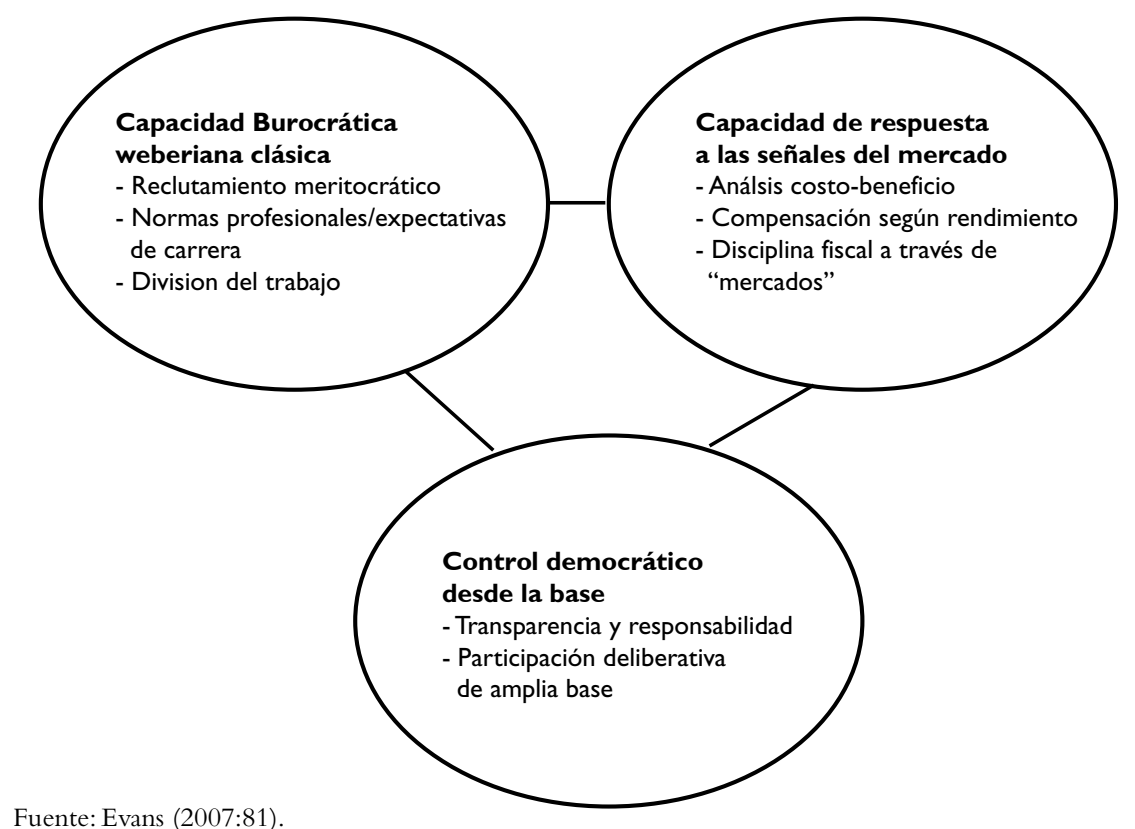

Fuente: Evans (2007:81)

\section{Bibliografía}

\section{Argentina. Constitución Nacional}

Decreto 993/91. Sistema Nacional de la Profesión Administrativa.

Decreto 447/93. Convenios colectivos para trabajadores del Estado. Reglamentación de la ley 24185. 1993.

Decreto 92/95. Establécese la reglamentación que determina las condiciones bajo las cuales se autorizará la contratación de personal especializado.

Decreto 103/00. Modernización del Estado.

Decreto 1184/0. Sustitúyese el régimen de contrataciones reglamentario del artículo 47 de la Ley $N^{\circ} 11.672$ (t.o.1999), aprobado por Decreto $N^{\circ}$ 92/95.

Decreto 1421/02. Reglamentario de la Ley Marco de Regulación del Empleo Público. Nacional. 
Decreto 214/06. Convenio Colectivo de Trabajo General para la Administración Pública Nacional.

Decreto 2098/08. Sistema Nacional de Empleo Público

Decreto 2345/08. Establécense los nuevos perfiles y el régimen retributivo para las contrataciones de los consultores profesionales.

Ley 24185. Convenios colectivos para trabajadores del Estado. 1992.

Ley 25164. Ley marco de regulación de empleo público nacional. 1999.

Subsecretaría de Presupuesto "El Sistema Presupuestario Público en la Argentina" http://www.mecon.gov.ar/onp/html/manuales/el_sistema_presupues-tario_publico.pdf. acceso 25-6-13

Bresser Pereira, Luiz Carlos (1999). Reforma del Estado para la ciudadanía. La reforma gerencial brasileña en la perspectiva internacional. Buenos Aires, CLAD-EUDEBA.

Centro Latinoamericano de Administración para el Desarrollo (CLAD) (1998). Una Nueva Gestión Pública para América Latina. http://www.clad.org/docu-mentos/declaraciones/una-nueva-gestion-publica-para-america-latina/view. Acceso 25-6-13

Christensen, Tom y Per Lægreid (2007). "Reformas post nueva gestión pública. Tendencias empíricas y retos académicos” Gestión y Política Pública. Volumen XVI. Número 2 .

Cormick, Hugo (2009). "Diversidad en las modalidades de empleo público. El caso de la Auditoría General de la Nación” Revista de la Asociación Argentina de Presupuesto y Administración Financiera Pública (ASAP). 41:33-84.

Cormick, Hugo y otros (2012). Informe de investigación: "Programa de Estudio sobre Empleo Público”. Departamento de Economía y Administración. Licenciatura en Administración. Universidad Nacional de Moreno.

Evans, Peter (2007). "El hibridismo como estrategia administrativa: combinando la capacidad burocrática con las señales de mercado y la democracia deliberativa" Transformación, Estado y Democracia. 35

Klingner, Donald E. y John Nalbandian (2001). La administración del personal en el sector público. México, Mc Graw Hill. $4^{\mathrm{a}}$ ed.

Lindenboim, Javier y Graña, Juan M. (2006). Empleo y remuneraciones en el sector público. La situación luego de los cambios de los noventa y recientes. Documento de Trabajo $N^{\circ}$ 6. Instituto de Investigaciones Económicas. Facultad de Ciencias Económicas. Universidad de Buenos Aires. CEDEP (Centro de Estudios sobre Población, Empleo y Desarrollo).

Longo, Francisco (2004). Mérito y flexibilidad. La gestión de las personas en las organizaciones del sector público. Barcelona, Paidós.

(2006). "Oferta y demanda de gerentes públicos. Un marco de análisis de la institucionalización de la dirección pública profesional” Reforma y Democracia. 35. http://www.clad. org/portal/publicaciones-del-clad/revista-clad-reforma-democracia/articulos/035junio-2006. pp. 1-16. Acceso 25-6-13

Longo, Francisco y Carles Ramió (eds.) (2008) “Introducción” [en] La profesiona- 
lización del empleo público en América Latina. Fundación CIDOB, Barcelona.

Lozano, Claudio (Coordinador) (2008). Las inconsistencias del indice salarial del sector público. Un análisis a la luz de los datos oficiales. Buenos Aires. CTA. Instituto de Estudios y Formación.

Oszlak, Oscar (1980) "Políticas públicas y regímenes políticos: reflexiones a partir de algunas experiencias latinoamericanas" [en] Estudios CEDES, vol. 3, No. 2, Buenos Aires. (1984) "Notas críticas para una teoría de la burocracia estatal” Teoría de la burocracia estatal. Buenos Aires, Paidós.

(2001) "El servicio civil en América Latina y el Caribe: situación y retos futuros” Documento presentado como ponencia en elVI Congreso Internacional del CLAD sobre la Reforma del Estado y la Administración Pública, Argentina.

Prats i Catalá, Joan (1995). "Los fundamentos institucionales del sistema de mérito: la obligada distinción entre función pública y empleo público” en Documentación Administrativa, Madrid, INAP, enero-agosto. Citado por Longo (2004) cit. pp. 71-72.

(2001) "Reinventar la burocracia y construir la nueva gerencia pública". Biblioteca de ideas. Documentos $n^{\circ}$ 63. Instituto Internacional de Gobernabilidad. Universidad Oberta de Catalunya. Barcelona

Ramió Matas, Carles (2006). "Política y Gestión: La Regulación del Rol del Directivo Público". II Congrès Català de Gestió Pública. Barcelona,

Salas, Eduardo (2006) "Empleo público y gobernanza democrática: reflexiones desde la experiencia argentina" Seminario Internacional sobre Modernización del Estado. Ciudad Autónoma de Buenos Aires, 26 y 27 de octubre

Sánchez Morón, Miguel (coord.) (2007). La Función Pública directiva en Francia, Italia y España. Madrid. INAP.

Schweinheim, Guillermo F. F. (2004). "Un Enfoque Institucional de la Reforma Administrativa en la Argentina.” Asociación Internacional de Presupuesto Público.

http://www.asip.org.ar/es/content/un-enfoque-institucional-de-la-reforma-administrativa-en-la-argentina. acceso 25-6-13

(2011) “¿Un nuevo desarrollo en América Latina? Implicancias en las políticas públicas, el Estado y la Administración” Reforma y Democracia. 49. http://www.clad.org/portal/ publicaciones-del-clad/revista-clad-reforma-democracia/articulos/049-febrero-2011/ Schweinheim.pdf. acceso 25-6-13

Zeller, Norberto y Rivkin, Ana (2003). El empleo en la Administración Pública Nacional: Estudio de la distribución de cargos y de las características de sus remuneraciones. Instituto Nacional de la Administración Pública. Dirección de Estudios e Información. Serie I: Desarrollo Institucional y Reforma del Estado. Documento Nº 69.

Páginas web oficiales

www.indec.gob.ar

www.mecon.gob.ar

www.sgp.gob.ar 